\title{
NOVOS MODELOS ORGANIZACIONAIS: PARADOXOS E CONTRADIÇÕES ENTRE O DISCURSO E A PRÁTICA
}

\author{
Reynaldo Cavalheiro Marcondes \\ Universidade Presbiteriana Mackenzie \\ E-mail: reynaldo@mackenzie.com.br
}

\author{
Isabella Freitas Gouveia de Vasconcelos \\ FGV-EAESP \\ E-mail: ivasconcelos@yahoo.com
}

\section{Flávio Carvalho de Vasconcelos \\ FGV-EAESP \\ E-mail: fcvasconcelos@fgvsp.br}

\author{
André Ofenhejm Mascarenhas \\ FGV-EAESP \\ E-mail: andremascar@gvmail.br
}

As organizações vivem atualmente uma época de dualidades. Isso por conta da transição do modelo industrial para o pós-industrial, que está redefinindo os papéis sociais e a política de gestão de pessoas nas organizações (Alter, 1990; Castells, 1999; De Masi, 1999; Sainsaulieu, 1977; 1983). Um dos pressupostos dessas análises é que organizações "controladoras" (Senge, 1990; Argyris, 1992) tenderiam a se transformar em organizações "em aprendizagem" (learning organizations) para se adaptarem à sociedade pós-industrial. Novas formas organizacionais são propostas, como as adocracias ou organizações inovadoras (Mintzberg, 2000), ou, ainda, as organizações interativas (Heckscher, 1994) (Heckscher et al., 2003).

Porém, muitas dessas mudanças se refletem nos modelos oficiais professados, mas não são implementadas na prática. A corrente neo-institucional ista mostra que freqü entemente as organizações incorporam estruturas e ferramentas não apenas porque sejam mais eficientes, mas também porque foram institucionalizadas em seu setor como sendo "as melhores", e a sua adoção passa a ser fonte de legitimidade e recursos no meio (Meyer e Rowan, 1991; Fonseca e M achado-da-Silva, 2001; Vasconcelos e Vasconcelos, 2001).

Meyer e Rowan mostram que, na verdade, a obediência estrita às normas é uma ficção. N a prática, existe o fenômeno do decoupling, ou seja, a separação en- tre as normas e a prática administrativa. Os indivíduos encontram espaços de ajuste à regra, seguindo-a apenas parcialmente. Muitos procedimentos são ritualizados e cerimonializados, possuindo a sua função social na organização, mas não são seguidos ao pé da letra (Meyer e Rowan, 1991).

Assim, vários indivíduos se sentem cobrados de acordo com os novos padrões propostos - como a participação, iniciativa e inovação - , quando na realidade não recebem treinamento nem condições para desenvolver novas competências e mostrar-se à altura dessas novas exigências de desempenho. Essa distância entre o que Ihes é exigido e as reais condições de trabal ho aumentam o medo e o estresse nas organizações (Lewis, 2000; Eisenhardt, 2000; Faria e M eneguetti, 2001).

$\mathrm{N}$ esse quadro de contradições atuais ressentidas pelos indivíduos em organizações, um conceito que parece explicar de modo satisfatório esses fenômenos é o de paradoxo, que volta a ser aplicado aos estudos organizacionais. Mas o que seriam paradoxos?

Segundo Lewis (2000), a fim de atribuir sentido aos sistemas contraditórios e ambíguos nos quais estão inseridos e compreendê-los, os indivíduos tem a tendência de polarizar suas percepções em torno de elementos opostos. Conseqüentemente, começam a agir em função dessa percepção polarizada, que corresponde à sua representação subjetiva da realidade. Os pro- 
blemas organizacionais e as interações sociais passam a ser descritos, pelos indivíduos e grupos, como variações de duas dimensões opostas que os confundem e incomodam, gerando dissonância cognitiva, ou conflito de crenças e percepções (Festinger, 1957; Bartunek, 1988; Vasconcelos et al., 2004).

Em resumo, um paradoxo é a representação da experiência, dos sentimentos, crenças e interações por meio de dois estados aparentemente inconsistentes, duas realidades opostas e aparentemente irreconciliáveis, como "autonomia e conformidade", "novo e veIho", "aprendizagem e mecanização do trabalho", "Iiberdade e vigilância" (Eisenhardt, 2000). A própria organização é representada pelos diversos grupos que a compõem de forma ambígua e dual.

Em se tratando de pesquisa, Teunissen (1996), em seu artigo "Paradoxes in social science and research", foi um dos pioneiros ao se referir ao tema dos paradoxos, e aos paradigmas de análise e pesquisa ligados a esse tema. U ma extensiva revisão da literatura real izada no Brasil, baseada em análise da literatura brasileira e estrangeira sobre o tema paradoxos organizacionais (Vasconcelos, 2004), mostrou que as principais correntes de pesquisa sobre o tema são:

- estudos baseados na crítica à burocracia e no controle burocrático: fundamentados nos trabal hos clássicos de Merton e Selznick sobre paradoxos organizacionais, vários autores atuais retomam os trabal hos clássicos, os revêem e atualizam;

- estudos baseados no paradigma psicodinâmico: fundamentados nos trabalhos clássicos do Instituto Tavistock de Londres nos anos 1950 (autores como Melanie Klein, Elliot Jacques e Bion), vários estudos atuais trabalham o conceito de paradoxos associados a esta linha de análise;

- estudos baseados na sociologia interpretativa e no interacionismo simbólico: vários trabalhos retomam a fenomenologia e os clássicos de Berger e Luckmann e Goffman para estudar temas como identidade, mudança, comunicação e análise do discurso, e papéis, associando-os ao tema paradoxos.

Esse trabal ho de revisão bibliográfica mostrou que, pertencendo a primeira corrente de crítica à burocracia, Merton, foi um dos primeiros autores a tratar do tema paradoxos organizacionais ao criticar a chamada ilusão de controle por parte dos gerentes e burocratas, e mostrando que esse controle não é possível, pois sempre existem disfunções. Merton descreve, assim, os problemas da personalidade burocrática: o excessivo apego às re- gras, e a busca de uma excessiva coerência e uma harmonia organizacional que não são possíveis. 0 autor alega que a contradição e o conflito são partes integrantes das organizações. Dessa forma, M erton (1936) afirma, em seu texto The U nanticipated Consequences of Purpposive Social Action, que toda ação social produz um paradoxo básico, tendo conseqüências contraditórias. Porque para cada efeito desejado de uma ação existe uma série de efeitos secundários, não desejados nem previstos, que se contrapõem aos efeitos buscados pelos indi víduos ao agir. Assim, para cada efeito "positivo" (intended consequence) existe um efeito que contraria as expectativas dos gerentes e administradores (unintendend consequence). A existência dessas contradições inerentes à ação social provoca, nas organizações, tensões que conduzem a fenômenos como a resistência organizacional e a emersão de conflitos (Merton, 1957).

Mckinley e Scherer (2000) atualizam essa perspectiva para as organizações atuais, analisando especialmente os processos de mudança e reestruturação organizacionais. Jafee (1999) também atualiza os trabaIhos de Merton, tratando do tema paradoxos dentro de uma perspectiva crítica (Bouchiki, 1998).

Em se tratando da segunda corrente, a revisão da literatura mostrou que os trabalhos de autores do Tavistock Institut, como Eric Trist, Harold Bridger, Elliot Jacques, Kennet Rice, Eric Miller, Wilfred Bion e M elaine Klein, são retomados por autores atuais dentro da perspectiva dos estudos sobre paradoxos e seus efeitos. Autores contemporâneos como Kets de Vries (1995), Yiannis Gabriel (1999) e Hirschhorn (1997) fundaram a International Society for the Psychoanalytic Study of Organizations, e o tema paradoxos organizacionais tem sido recorrente em seus trabal hos. Em uma linha de estudos de origem francesa, autores como Christophe Dejours (1987), Enriquez (1991), Vincent de Gaullejac, Pagès (1987), Alain Chanlat e JeanFrançois Chanlat (1996) tratam desse tema.

Finalmente, em se tratando da terceira corrente, os estud os baseados na sociologia interpretativa e no interacionismo simbólico seguem a perspectiva weberiana do estudo da ação social, e consideram que os valores de um indivíduo não determinam sua decisão, sua forma de agir nem seu comportamento. Tampou co novas formas de ação e comportamento determinam necessariamente a adoção de novos valores pelo indivíduo. Este pode reafirmar seus valores antigos. Essas duas variáveis não seriam explicadas por uma lógica linear de causa e efeito, mas constituiriam um sistema. Mostram que, ao conhecer a real idade complexa e representá- 
la a fim de tomar uma decisão, em seu processo de escolha, os indivíduos tendem a representar essa mesma realidade a partir de duas dimensões opostas - crenças, valores, perspectivas, sentimentos -, e o processo decisório reduz o "desconforto" provocado pela oposição entre esses elementos subjetivos básicos. 0 sujeito, porém, freqüentemente terá que conviver com tensões entre pólos opostos, pois esse confronto faz parte de sua atividade perceptiva e cognitiva, e de seu processo de evolução. Nem toda decisão gera polarização em torno de dimensões opostas, mas freqü entemente em sua vida o sujeito se vê às voltas com os efeitos do paradoxo gerado pelo processo de dissonância cognitiva, principalmente quanto às interações, experiências ou perspectivas que 0 afetam pessoal mente (Ford e Ford, 1988). 0 conceito de paradoxo está, assim, nessa corrente, associado ao conceito de lógica de ator, ou seja, à formação dos valores, critérios de decisão e escolhas, bem como à representação da realidade de cada indivíduo ou grupos de indivíduos. Em suma, de acordo com essa corrente, a representação da realidade por meio de elementos opostos e conflitantes - os paradoxos - é um elemento inerente ao ato de conhecer e ao processo de tomada de decisão do ser humano, e como base teórica está associada à teoria da racionalidade limitada.

A revisão da literatura mostrou também a utilização de métodos qualitativos e quantitativos ao tratar do tema paradoxos organizacionais. A utilização desses métodos de pesquisa é normal mente coerente com o paradigma teórico utilizado, e os métodos são utilizados de forma complementar. Em um paradigma que trata dos paradoxos organizacionais de forma positivista, utilizam-se normalmente métodos quantitativos. Em um paradigma interpretacionista ou crítico, é usual a utilização de métodos mais qualitativos, ou uma metodologia mista.

\section{O FÓRUM}

Com o objetivo de estimular a produção de pesquisas e artigos que contribuam para o desenvolvimento do tema no Brasil, foi realizado na sede da RAE o fórum "N ovos modelos organizacionais: paradoxos e contradições entre o discurso e a prática", que ora apresentamos. Foram submetidos 36 artigos, oito dos quais foram aprovados para publicação, após passarem por rigorosos e sucessivos processos de avaliação e aperfeiçoamento. N uma iniciativa inédita, dos oito artigos aprovados, três estão sendo publicados na RAE impressa e cinco deles, na RAE-eletrônica.

Nesta edição da RAE, o primeiro artigo do fórum, "Ars antiqua: Mosteiro de São Bento, o eterno no tempo", de Mercya Rose de Oliveira Carval ho e Tânia Maria Dresden Fischer, investiga a condição de instituição total da Ordem Beneditina, a partir da experiência do Mosteiro de São Bento, na Bahia. Trata-se de pesquisa Iongitudinal que mapeou as mudanças ocorridas na gestão do mosteiro, no período entre 1994 e 2004. 0 artigo, ao mapear os paradoxos e contradições no percurso histórico dessa organização no decorrer do tempo, traz uma contribuição fundamental para este fórum.

0 segundo artigo, "N omadismo involuntário na reestruturação produtiva do trabal ho bancário", de Carmem Ligia Iochins Grisci, Gilles Chemale Cigerza, Pedro M endes Hofmeister e João Luiz Becker, analisa as conseqüências organizacionais e os paradoxos encontrados em um processo de reestruturação do trabalho bancário. Anal isa ainda as contradições organizacionais e 0 sofrimento psíquico decorrentes do processo de reestruturação e mudança organizacional, utilizando uma metodologia mista, qual itativa e quantitativa.

0 terceiro trabal ho, "Paradoxos em finanças: teoria moderna versus finanças comportamentais", de Herbert Kimura, Leonardo Fernando Cruz Basso e Elizabeth Krauter, trata de uma das inovações mais importantes e controversas em finanças, que confronta o paradigma tradicionalmente aceito, baseado na moderna teoria financeira. Os autores realizam uma síntese de potenciais problemas de tomada de decisão, exemplificando alguns aspectos não racionais que constituem importantes paradoxos em finanças. A pós uma discussão da teoria de prospecto, os autores replicam os experimentos de Kahneman e T versky numa amostra brasileira. Os resultados sugerem que as finanças comportamentais são uma al ternativa útil para explicar o comportamento dos agentes econômicos.

Os artigos revelam que o estudo dos processos de comunicação nas organizações torna-se fundamental atualmente, neste contexto de mudança transformacional que as organizações vivenciam. No entanto, o estudo dos processos de mudança organizacional e paradoxos mostra que classificações como "industrial" e "pós-industrial", "moderno" e "pós-moderno" são muitas vezes exageradas. Os artigos neste fórum mostram que o passado não se opõe necessariamente ao futuro, sendo as contradições um caminho para a construção do novo em um processo dialético que nunca se finaliza. 


\section{REFERÊNCIAS BIBLIOGRÁFICAS}

ALTER, N. Logiques de l'entreprise informationnelle. In: Revue Française de Gestion, juin-juillet-août, p. 29-39, 1990.

ARGYRIS, C. On Organizational Learning. Cambridge, MA: Blackwell, 1992.

BARTUNEK, J. M. The dynamics of personal and organizational reframing. In: QUINN, R. E.; CAMERON, K. (Eds.). Paradox and Transformation: Toward a Theory of $C$ hange in O rganization and $M$ anagement. Cambridge, MA: Ballinger, 1988. p. 137-162.

BERGER, P.; LUCKMANN , T. A construção social da realidade. Petrópolis: Vozes, 1989.

BION, W. R. Experiences in Groupes. N ew York: Basic Books, 1959.

BOUCHIKI, H. Living with and building on complexity: a constructivist perspective on organizations. Organization, v. 2, p. 217-232, 1998.

CAMERON, K. S.; QUINN, R. Organizational paradox and transformation. In QUIN N, R. E.; CAMERON, K. S. (Eds.) Paradox and transformation: Toward a Theory and Change in Management. Cambridge, MA: Ballinger, 1998. p. 12-18.

CASTELLS, M. A sociedade em rede. São Paulo: Paz e Terra, 1999.

DE MASI, D. 0 futuro do trabalho: fadiga e ócio na sociedade pós-industrial. Rio de Janeiro: José Olympio, 2000.

DEJOURS, C. Intelligence pratique et sagesse pratique: deux dimensions meconnues du travail réel". Education Permanente, n. 116, p. 22-34, 1993.

EISENHARDT, K. M. Paradox, spirals, ambivalence: the new language of change and pluralism. The Academy of M anagement Review, v. 25, n. 4, p. $703-706,2000$.

EISENHARDT, K. M.; WESTCOTT, B. J. Paradoxical demands and the creation of excellence: the case of just-in-time manufacturing. In: QUINN, R. E.; CAMERON K. S. (Eds.). Paradox and Transformation: Toward a Theory of Change in Organization and Management. Cambridge, MA: Ballinger, 1988. p. 169-194.

ENRIQUEZ, E. L'organisation en analyse. Paris: P.U.F., 1991.

FARIA, J. H.; MENEGUETTI, F. Discursos organizacionais. In: ENCONTRO NACIONAL DA ASSOCIAÇÃO NACIONAL DOS PROGRAMAS DE PÓS-GRADUAÇÃO E PESQUISA EM ADMINISTRAÇÃO, 25., 2001, Campinas-SP. Anais. Campinas-SP: AN PAD, 2001.

FONSECA, V. E.; MACHADO-DA-SILVA, C. 0 indivíduo, a organização e o ambiente: bases para a conversação entre três perspectivas de estudo da estratégia em organizações. In: EN CONTRO NACIONAL DA ASSOCIAÇÃO NACIONAL DOS PROGRAMASDE PÓS-GRADUAÇÃO E PESQUISA EM ADMINISTRAÇÃO, 25., 2001, Campinas-SP. Anais. Campinas-SP: ANPAD, 2001.

FORD, J. D.; FORD, L. W. Logics of identity, contradiction and attraction in change. Academy of M anagement Review, v. 19, p. 756-795, 1994.

HECKSCHER, C.; DON NELLON, A. The Post-Bureaucratic Organization. Thousands Oaks: Sage, 1994.
HECKSCHER, C.; MACCOBY, M.; RAMIREZ, R. Agents of Change: Crossing the Post-Industrial Divide. Oxford: Oxford University Press, 2003.

HIRSCHHORN, L. Reworking Authority. Cambridge, MA: The MIT Press, 1997.

JAFFEE, D. Organization theory: tensions and change. New York: M cGraw Hill, 1999.

KETS DE VRIES, M. F. R. Organizational Paradoxes: Clinical Approaches to Management. N ew York: Rudlege, 1995.

KOOT, W.; SABELIS, I.; YBEMA, S. Epilogue. In: KOOT, W.; SABELIS, I.; YBEMA, S. (Eds.). Contradictions in Context: Puzzling over Paradox in Comtemporary Organizations. Amsterdan: VU University Press, 1996. p. 208-212.

LEONARD-BARTON, D. Core capabilities and core rigidities: a paradox in managing new product development. Strategic M anagement Journal, $v$. 13, p. 111-125, 1992.

LEWIS, M. W. Exploring paradox: toward a more comprehensive guide. The Academy of Management Review, v. 25. n. 4, p. 760-776, 2000.

MCKINLEY, W.; SCHERER, A. G. Some unanticipated consequences of organizational restructuring, The Academy of Management Review, v. 25. n. 4, p. $735-752,2000$.

MERTON, R. Social Theory and Social Structure. Glencoe: Free Press, 1957.

MEYER, J. W.; ROWAN , B. Institutionalized organizations: formal structure as myth and ceremony, In: POWELL W.; DIMAGGIO P. (Eds.). The New Institutionalism in Organizational Analysis. Chicago: The University of Chicago Press, 1991. p. 41-62.

MINTZBERG, H. Criando organizações eficazes. São Paulo: Atlas, 2000.

PAGÈS, M.; BONETTI, M.; GAULEJAC, V.; DESCENDRE, D. L' emprise de l'organisation. Paris: P.U.F., 1991.

PESQUEUX, I.; RAMANANTSOA, B.; SAUDAN , A.; TOURNAND, J.C. Mercure et M inerve: perspectives philosophiques sur l'entreprise. Paris: Ellipses, 1999.

POWELL, W.; DIMAGGIO, P. The N ew Institutionalism in Organizational Analyses. Chicago: Chicago University Press, 1991.

SAINSAULIEU, R. L'identité au travail. Paris: Presses de la Fondation Nationale de L'Institut d'Études Politiques, 1977.

SAINSAULIEU, R. La régulation culturelle des ensembles organisés. L'Année Sociologique, p. 195-217, 1983.

SENGE, P. The Fifth Discipline: The Art and Practice of the Learning Organization. New York: Doubleday, 1990.

VASCONCELOS, F.; VASCONCELOS, I. The limits of ISO 9000 consulting methods: towards a multidimensional approach. Washington: Academy of Management Conference, 2001.

VASCONCELOS, F.; VASCONCELOS, I. Paradoxos organizacionais. São Paulo: Thomson Learning Pioneira, 2004.

\section{Artigo convidado. Aprovado em 30.11.2005.}

